\title{
Effect of Processing Route on the Microstructure and Mechanical Properties of Hot Work Tool Steel
}

\author{
Robert Besler, Markus Bauera, Kaline Pagnan Furlan ${ }^{a, b}$, Aloisio Nelmo Klein ${ }^{b}$, Rolf Janssen * \\ ${ }^{a}$ Institute of Advanced Ceramics, Hamburg University of Technology, Denickestrasse 15, 21073, \\ Hamburg, Germany. \\ ${ }^{b}$ Materials Laboratory - LabMat, Mechanical Engineering Department, Universidade Federal de \\ Santa Catarina, Campus Reitor João David Ferreira Lima, Bairro Trindade, CEP 88040-900, \\ Florianópolis, SC, Brazil.
}

Received: September 26, 2016; Revised: June 23, 2017; Accepted: July 21, 2017

\begin{abstract}
Powder metallurgy is a growing sector in industrial production, as it offers outstanding energy, cost and material savings in comparison with established processing routes such as casting. Hot work toll steels are usually produced by ingot metallurgy, but also by powder metallurgy, namely hot isostatic pressing and powder forging routes. In this paper we investigate the possibility of production of a hot work tool steel (AISI H13) by conventional (die compaction and pressureless sintering) and metal injection molding routes, aiming to reduce cost and production time. The sintering behavior was studied from $1250^{\circ} \mathrm{C}$ until $1430^{\circ} \mathrm{C}$ and the resulting parts were compared in terms of microstructure, hardness and tensile strength. The results showed that both shaping routes together with pressureless sintering are suitable to produce this alloy. By combining the best shaping approach and a tailored sintering cycle, it was possible to produce samples with $400 \mathrm{HV} 10$ as well as tensile strength of 1 $\mathrm{GPa}$, which are comparable to the ones obtained by powder forging.
\end{abstract}

Keywords: powder metallurgy, steel, dilatometry, hardness measurement, mechanical characterization.

\section{Introduction}

There are basically three major groups of tool materials: cold work tool steels (CWS), hot work tool steels (HWS) and high speed tool steels (HSS) ${ }^{1}$. CWS are used for temperatures up to $200^{\circ} \mathrm{C}$ and can be furthermore distinguished in three groups containing different amounts of carbon (from 0.4 up to $2.3 \mathrm{wt}$ \%). Depending on the amount of carbon this type of tool steel can contain a high fraction of carbides which improves its wear resistance. HWS are deployed when application temperatures of $200^{\circ} \mathrm{C}$ and more are required. In order to resist the applied cyclic loading HWS have a higher tenacity than CWS, containing less C. Just like CWS, HWS can be distinguished in three groups. Each group relies on different demands in temperature load. HSS combine the abrasion resistance of CWS with the thermal strength of HWS $^{2}$.

Among the HSW steels is the AISI H13 (also known as X40CrMoV5-1), mainly used for die casting and forging, extrusion moulding as well as pipe and glass-making ${ }^{3}$. It has a high amount of alloy elements as well as an considerable secondary hardness. Molybdenum (Mo) and vanadium (V) provide the coarsening of carbides which increases the thermal stability ${ }^{4}$. It is desired that HWS do not undergo phase transitions in its application ${ }^{1}$.

The route used to produce the HWS has a major influence in its properties. The majority of HSW are produced by ingot metallurgy. Since the 1980's HWS are also processed using powder metallurgy (PM), being hot isostatic pressing (HIP) the most established method ${ }^{1,5}$, as well as powder forging ${ }^{6}$. In comparison to cast products, PM enables to achieve higher homogeneity, smaller grain and carbides size as well as the prevention of macro-segregation ${ }^{7}$, thus resulting in superior mechanical properties associated with high dimensional accuracy and surface quality ${ }^{8}$.

While the PM conventional route (die compaction and sintering) is already extensively studied for cold work tool steels (CWS) ${ }^{9,10}$ and high speed tool steels (HSS) $)^{11-19}$, it is rather scarcely used for HWS. At present, there is hardly any literature characterizing HWS using PM methods apart from HIP $^{20}$. In order to use conventional PM, knowledge about 
the sintering behavior as well as mechanical properties characterization has to be generated.

Powder metallurgy also offers the possibility to use HSW in ceramic reinforced composite materials (which is a project future goal), for which MIM becomes a very interesting process, as the compaction of small ceramic powders is very difficult without a granulation step. In the present paper, we studied the possibility to produce a hot work tool steel (AISI H13) by die compaction or powder injection molding combined with pressureless sintering, a less costly and time consuming route when compared with HIP or powder forging. At first it was analyzed the sintering behavior of this steel for temperatures ranging from 1250 ${ }^{\circ} \mathrm{C}$ (typical for metal processing) until $1430{ }^{\circ} \mathrm{C}$ (typical for ceramic processing). The influence of processing parameters, namely the shaping route and sintering temperature, in the microstructure, as well as its relation with the mechanical properties, are discussed. Using powder injection molding and pressureless sintering it was possible to achieve mechanical properties values comparable with the ones obtained by the HIP route.

\section{Experimental Procedure}

The AISI H13 gas atomized steel powder was supplied by the company TLS Technik GmbH \& Co. Spezialpulver $\mathrm{KG}$. The powder chemical composition is listed in Table 1.

The particle shape of the delivered powder is spherical with particle sizes of $\mathrm{d}_{10}=5.30 \mu \mathrm{m}, \mathrm{d}_{50}=12.47 \mu \mathrm{m}$ and $\mathrm{d}_{90}$ $=23.10 \mu \mathrm{m}$ (CILAS 990 NASS particle size analyser and Malvern Mastersizer 3000). The powder morphology as well as the particle size distribution are shown at Figure 1.

Table 1. Chemical composition of starting powder in wt.- $\%$.

\begin{tabular}{lcccccc}
\hline Fe & C & Cr & Mo & V & Mn & Si \\
\hline Balance & 0.37 & 5.0 & 1.3 & 0.98 & 0.44 & 1.0 \\
\hline
\end{tabular}

The samples were processed by powder metallurgy using two different shaping approaches: uniaxial die compaction and powder injection molding (PIM).

For the uniaxial mechanical pressing, the AISI H13 powder needed to be granulated in order to guarantee suitable flowability and compressibility. For granulation, paraffin (2.5 wt.\%) was slowly dissolved in $35 \mathrm{ml}$ hexane and then homogenized with the powder in a cylindrical shaped container with continuous rotation. The resulting compound was sieved and granulated in the fraction between $500 \mu \mathrm{m}$ and $88 \mu \mathrm{m}$, which was used for the die compaction. Paraffin was later removed in a thermal debinding cycle.

Compaction by mechanical pressing was executed with a single action uniaxial hand-lever Skay press (product code: 1663). All the compacted specimens were cylindrical shaped with a diameter of $10 \mathrm{~mm}$ and an average length of $6.9 \mathrm{~mm}$. To evaluate the compressibility, pressures between $300 \mathrm{MPa}$ and $1000 \mathrm{Mpa}$ were applied for $10 \mathrm{~s}$. After evaluating the compressibility curve, a pressure of $700 \mathrm{Mpa}$ was used for producing the samples, where no delamination was observed.

For powder injection molding a binder system (Table 2) was added to the powder. Each mixture was composed by 1.2 $\mathrm{kg}$ of powder and was mixed in a HAAKE Rheomix 3000 Lab Mixer. The internal mixer was equipped with two rotors rotating at $60 \mathrm{RPM}$ compounding the mixture for $60 \mathrm{~min}$ at a temperature of $180^{\circ} \mathrm{C}$. Thereby, the increased temperature enhanced a homogeneous mixing of the powder material. After cooling down to room temperature in ambient atmosphere the feedstock was pelletized by the Seibt MGHS 3/180. For injection molding, an Arburg Allrounder 320s was used. The barrels' temperature at the injection machine were set to $165^{\circ} \mathrm{C}$ in the first section with incremental increase by $5^{\circ} \mathrm{C}$ up to $185^{\circ} \mathrm{C}$ at the nozzle, a hydraulic injection pressure of 100 Mpa and a speed of $0.03 \mathrm{~m} / \mathrm{s}$ were used within a $13 \mathrm{~s}$ cycle. Test samples in form of dog bones (MPIF 10), flat tensile rods (ASTM E8) and cylindrical samples were produced.
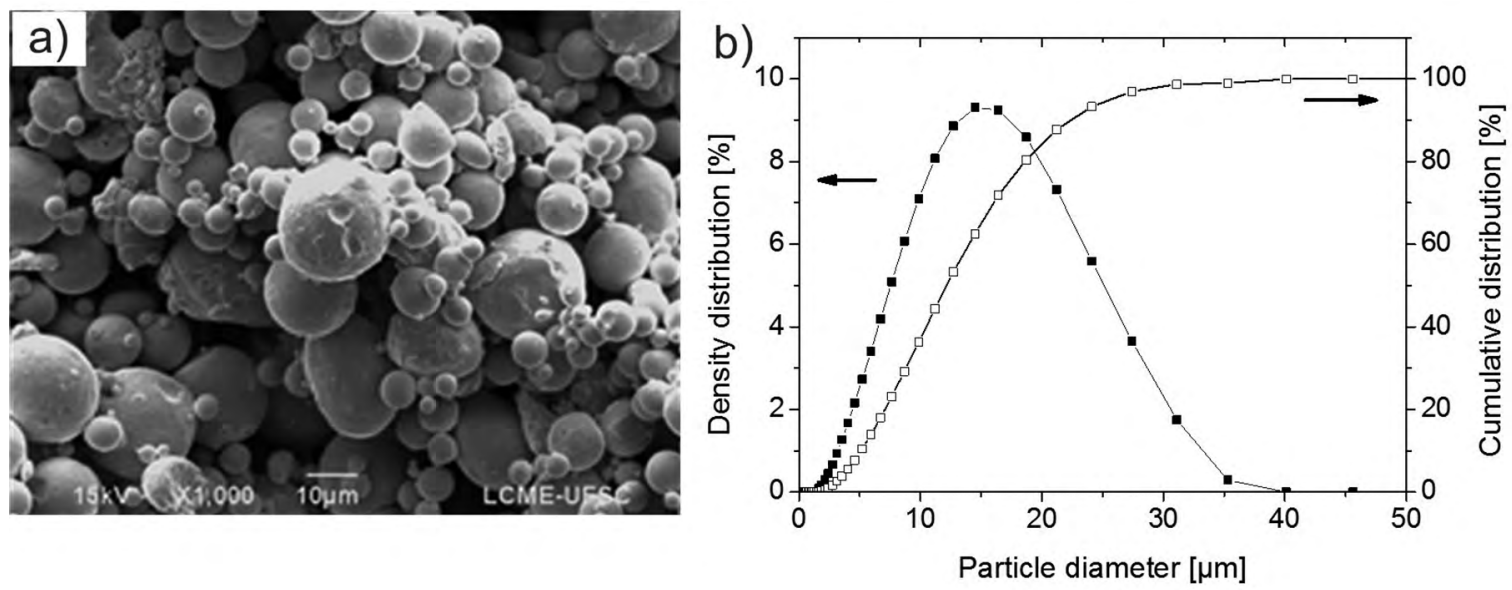

Figure 1. Starting powder a) SEM showing the particle morphology and b) particle size distribution. 
Table 2. Binder system used in the powder injection molded samples.

\begin{tabular}{cccccc}
\hline & Polypropylene & Paraffin & Ethylene-vinyl acetate & Amide Wax & Anti-Oxidants \\
\hline Binder system in vol.\% & 17.5 & 15.4 & 6.5 & 2.0 & 0.1 \\
\hline
\end{tabular}

For the compacted (pressed) parts thermal debinding was the first step of the sintering cycle, as described later on. On the other hand, injection molded parts were debinded in two stages, a chemical and a thermal one. For chemical debinding, injection molded samples were placed on a metallic sieve above a 3 liters hexane container. In a first stage, hexane was kept for two hours at $55^{\circ} \mathrm{C}$, so the vaporized hexane could enter the samples. The samples were then immersed completely in hexane. The temperature was kept constant at $55^{\circ} \mathrm{C}$ for another 10 hours. After a total of 12 hours the samples were taken out still containing a fraction of a backbone polymer which was extracted in a subsequent thermal debinding step.

The thermal debinding process was performed in a reducing gas atmosphere (100\% hydrogen, purity 99.999 , $200 \mathrm{sccm}$ flow) under $1.33 \mathrm{hPa}$ (1 Torr) in a plasma assisted furnace (PADS-LabMat/UFSC). From room temperature up to $300{ }^{\circ} \mathrm{C}$ the temperature was increased by $5{ }^{\circ} \mathrm{C} / \mathrm{min}$, followed by $0.5{ }^{\circ} \mathrm{C} / \mathrm{min}$ to $500{ }^{\circ} \mathrm{C}$ and finally $5{ }^{\circ} \mathrm{C} / \mathrm{min}$ up to $700{ }^{\circ} \mathrm{C}$. After a dwell time of $60 \mathrm{~min}$ at $700{ }^{\circ} \mathrm{C}$, the cooling was carried out inside the furnace (heater elements off). The pulse width of the plasma source was increased during heating up to $100 \mu \mathrm{s}$ (microseconds) and reduced to $10 \mu$ s during cooling.

At first the sintering behavior of the samples was investigated in a push-rod dilatometer (Netzsch DIL $402 \mathrm{C}$ ). Using an atmosphere of hydrogen and $\operatorname{argon}\left(95 \% \mathrm{Ar} 5 \% \mathrm{H}_{2}\right)$ at $1 \mathrm{~atm}$ $(1013.25 \mathrm{hPa})$ with a heating rate of $10^{\circ} \mathrm{C} / \mathrm{min}$ to sintering temperatures ranging from $1250{ }^{\circ} \mathrm{C}$ to $1430{ }^{\circ} \mathrm{C}$, where the samples were kept for 60 minutes. Titanium chips were used as oxygen gathers, aiming to reduce the oxygen content in the atmosphere ${ }^{21}$. DTA and TG were performed at a heating rate of $10{ }^{\circ} \mathrm{C} / \mathrm{min}$ until $1500{ }^{\circ} \mathrm{C}$ in the same atmosphere. Linear shrinkage was calculated by the dilatometer push rod displacement, while the volumetric shrinkage was calculated though the measurement of samples' dimensions (diameter and height) right before and after sintering. In addition, sintering was performed in a tubular furnace (Institute of Advanced Ceramics) at $1350{ }^{\circ} \mathrm{C}$.

Samples weight (Metler Toledo X205 resolution 0.01 $\mathrm{mg}$ ) and dimensions (caliper Mitutoyo resolution 0.001 $\mathrm{mm}$ ) were controlled during the whole processing. For green and sintered samples the density was calculated by the geometrical method. For sintered samples the density was also measured using the Archimedes method (Metler Toledo X205).

After sintering the resulting microstructures were characterized by optical microscopy (Olympus BX60, samples etched by Marble), scanning electronic microscopy
(SEM - JEOL JSM-6390LV), energy-dispersive X-ray spectroscopy (EDS) and Vickers hardness (Zwick 3212), with a test force of $98.07 \mathrm{~N}$. For samples sintered in the tubular furnace the tensile strength was measured according to DIN EN ISO 6892-1 (2009).

\section{Results and Discussion}

The online dimensional variation of the green compacts, both pressed and injection molded, measured during sintering in a dilatometer is shown in Figure 2.

For the pressed sample (Figure2-A) temperature plays a critical role, in which a $30^{\circ} \mathrm{C}$ shift in the sintering temperature (from 1400 to $1430{ }^{\circ} \mathrm{C}$ ) lead to an increase of $18.5 \%$ in the linear shrinkage while a $150{ }^{\circ} \mathrm{C}$ shift $\left(1250\right.$ to $\left.1400{ }^{\circ} \mathrm{C}\right)$ only lead to a $1.5 \%$ increase. This behavior indicates the possible formation of a liquid phase for temperatures above $1400{ }^{\circ} \mathrm{C}$, in agreement with the phase diagram for this alloy (Figure 3 ) that indicates a liquid phase formation at $\sim 1385$ ${ }^{\circ} \mathrm{C}$. For all the cycles, no indentation of the pushrod into the sample was observed.

On the other hand, injection molded samples (Figure 2-B) presented a different behavior, where linear shrinkage increased slightly with the temperature (better visualized in Figure 4). Still, for the highest sintering temperature $\left(1430{ }^{\circ} \mathrm{C}\right)$, the same linear shrinkage of the pressed sample ( $\sim 25 \%$ ) was observed. Figure 4 (grey square) indicates that the volumetric shrinkage of the samples is reduced at 1400 ${ }^{\circ} \mathrm{C}$, due to a swelling in the diameter.

The density results (Figure 5) showed that there is no further densification at temperatures higher than $1400{ }^{\circ} \mathrm{C}$ (injection molded) and $1375^{\circ} \mathrm{C}$ (pressed). This means that even though the samples exhibit an increase in the linear and for some samples also volumetric - shrinkage (Figure 4), a rise to temperature above $1400{ }^{\circ} \mathrm{C}$ will not improve the densification. For injection molded samples, sintering at the highest temperature $-1430{ }^{\circ} \mathrm{C}$ - led to the highest density obtained, e.g. $96 \%$ of theoretical density. While the gain in density between the initial three temperatures is clearly visible, it is slightly increasing from $1400{ }^{\circ} \mathrm{C}$ on. As the increase in density between $1400{ }^{\circ} \mathrm{C}$ and $1430{ }^{\circ} \mathrm{C}$ accounts to only $1.84 \%$.

Samples pressed uniaxially at $700 \mathrm{Mpa}$ exhibited a green density of $75 \pm 0.4 \%$ T.D., while in injection molded samples the relative green density is only $62.2 \pm 0.5 \%$ - as predetermined by the amount of binder. This means that the latter exhibit more voids, resulting in a larger shrinkage associated during sintering in the dilatometer. Even though, the injection molded samples had a larger shrinkage (see 

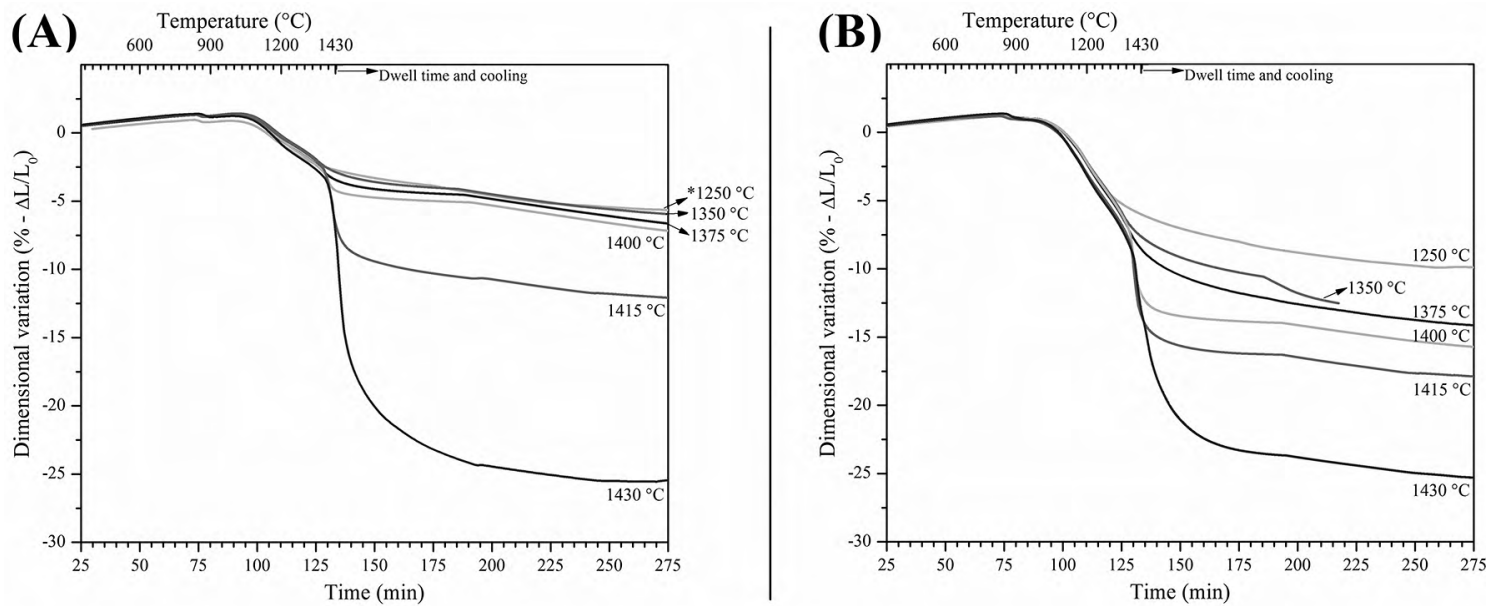

Figure 2. Dimensional behavior of (a) pressed and (b) injection molded samples during their sintering in a dilatometer (heating rate of $10{ }^{\circ} \mathrm{C} / \mathrm{min}$ up to the sintering temperature in a $5 \% \mathrm{H}_{2}+$ Ar gas flow).

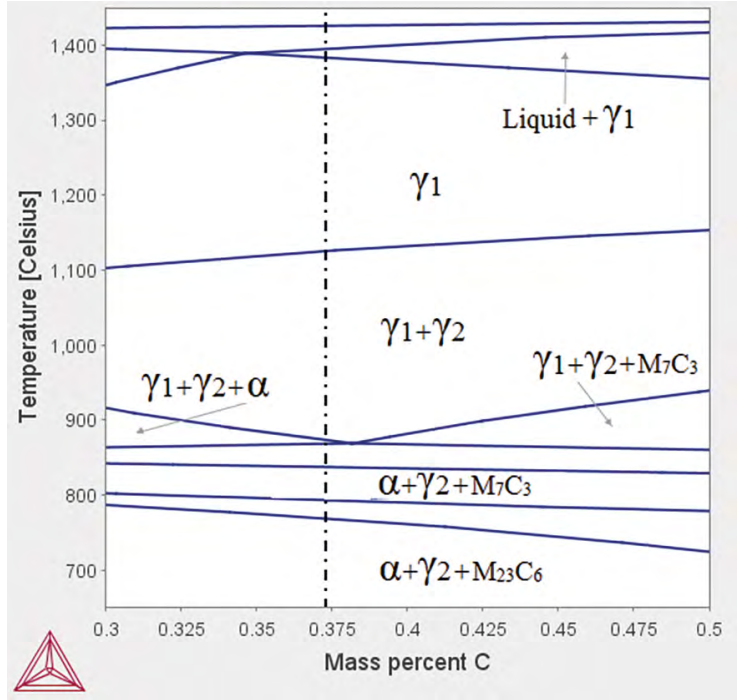

Figure 3. Phase diagram for the AISI H13 alloy (Thermocalc(r) software) according to the carbon content (wt.\%). The dashed line indicates the composition of the samples processed in this study.

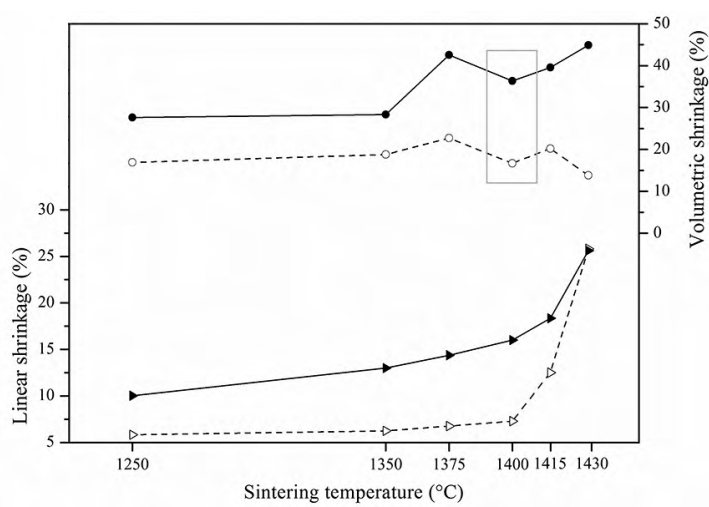

Figure 4. Evolution of linear and volumetric shrinkage of pressed (dashed line) and injection molded (solid line) samples according to the sintering temperature. The grey square marker indicates the temperature at which swelling occurred.

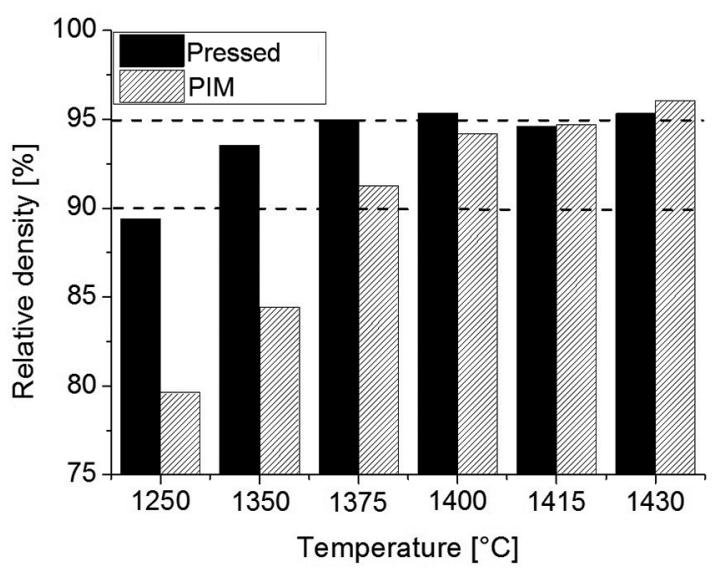

Figure 5. Final density for pressed and injection molded samples after sintering at temperatures between $1250^{\circ} \mathrm{C}$ and $1430^{\circ} \mathrm{C}$.

Figure $4,1350^{\circ} \mathrm{C}$ ), it achieved lower sintered densities in comparison with the pressed ones, for the same sintering temperature (Figure $5,1350^{\circ} \mathrm{C}$ ).

Sintering at temperatures higher than $1400{ }^{\circ} \mathrm{C}$ did not lead to a densification higher than $95 \%$ of theoretical density (Figure 5). The sintering cycles performed in the dilatometer (Figure 2) showed the possible formation of a liquid phase for sintering temperatures higher than $1375^{\circ} \mathrm{C}$, which caused dimensional instability.

During heating at approximately $80 \min \left(875^{\circ} \mathrm{C}\right)$ all the samples exhibited the transformation of iron from body-centered cubic (bcc, ferrite) alpha crystals to face-centered cubic (fcc, austenite) gamma form (Figure 6, dashed circular marker). During cooling the transformation from austenite to bainite occurred (Figure 6, ellipsoidal marker), which is in agreement with the CTT diagram for this alloy ${ }^{22,23}$.

The major phase in pressed as well as injection molded sintered samples is bainite, indicated by crystalline rod like structures (circle 1 in Figure 7-D). The lighter occurring areas consist of retained austenite (circle 2 in Figure 7-D). The 


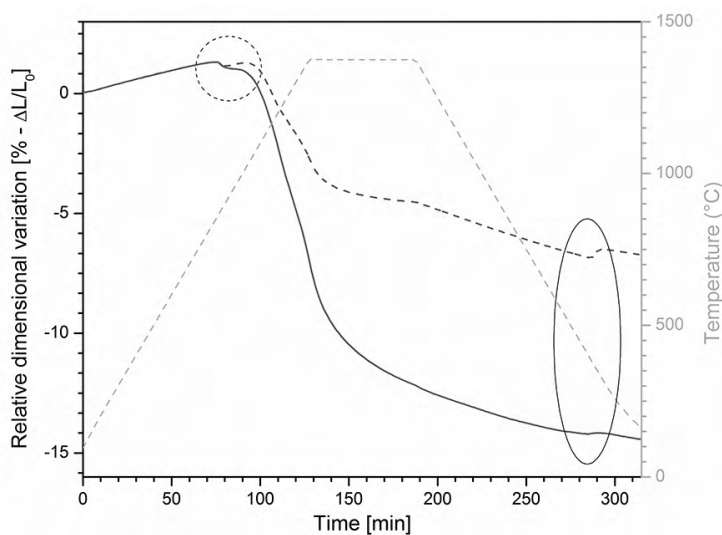

Figure 6. Sintering cycle (monitored in a dilatometer) of injection molded (solid) and pressed (dashed) specimens at $1375^{\circ} \mathrm{C}$ in an atmosphere of $95 \%$ argon and 5\% hydrogen.

microstructure of samples sintered at other temperatures mainly resembles those displayed in Figure 7, with small differences in the distribution and amount of austenite. Due to the low densification, injection molded samples sintered at 1250 and $1350{ }^{\circ} \mathrm{C}$ presented only few neck formations, with lack of continuity in the microstructure and large partly interconnected pores. For all other samples, pores are predominantly spherical, almost equally sized and distributed without any clusters.
Beside the similarities mentioned above, at temperatures exceeding $1375^{\circ} \mathrm{C}$ for injection molded samples and $1350{ }^{\circ} \mathrm{C}$ for pressed samples, the microstructure of the surface near region differed from the core region in terms of metallic phase as well as porosity (Figure 8). An EDS analysis (Table 3) shows the chemical composition of both areas, with different $\mathrm{C}, \mathrm{Mn}$ and $\mathrm{V}$ contents. This was caused by decarburization of the samples, which created a border region lacking Mn and $\mathrm{C}$. This is associated to a carbothermal reduction phenomena of surface oxides ${ }^{24}$, as observed by Danninger et al. ${ }^{25}$ in $\mathrm{Cr}$ pre-alloyed steels, where deoxidation takes place leading to a mass loss and formation of carbon-monoxide and carbondioxide $\left(\mathrm{CO} / \mathrm{CO}_{2}\right)$. Note that this carbon loss would cause the dashed line indicated in the phase diagram of the Figure 9 to move left, first increasing the temperature at which liquid phase happens, but for higher carbon losses, decreases it (the phase diagram was constructed based on the alloy composition as function of the carbon content). The carbon potential of the atmosphere is defined by the ratio of $\mathrm{CO}$ to $\mathrm{CO}_{2}$ or by the dew point ${ }^{26}$ or oxygen level at a particular temperature and concentration of $\mathrm{CO}$ and $\mathrm{H}_{2}{ }^{27}$. If the water, hydrogen or oxygen content is too high, decarburization by reaction with the atmosphere may occur ${ }^{26}$. In such cases there is also the possibility of Mn oxidation ${ }^{28}$.
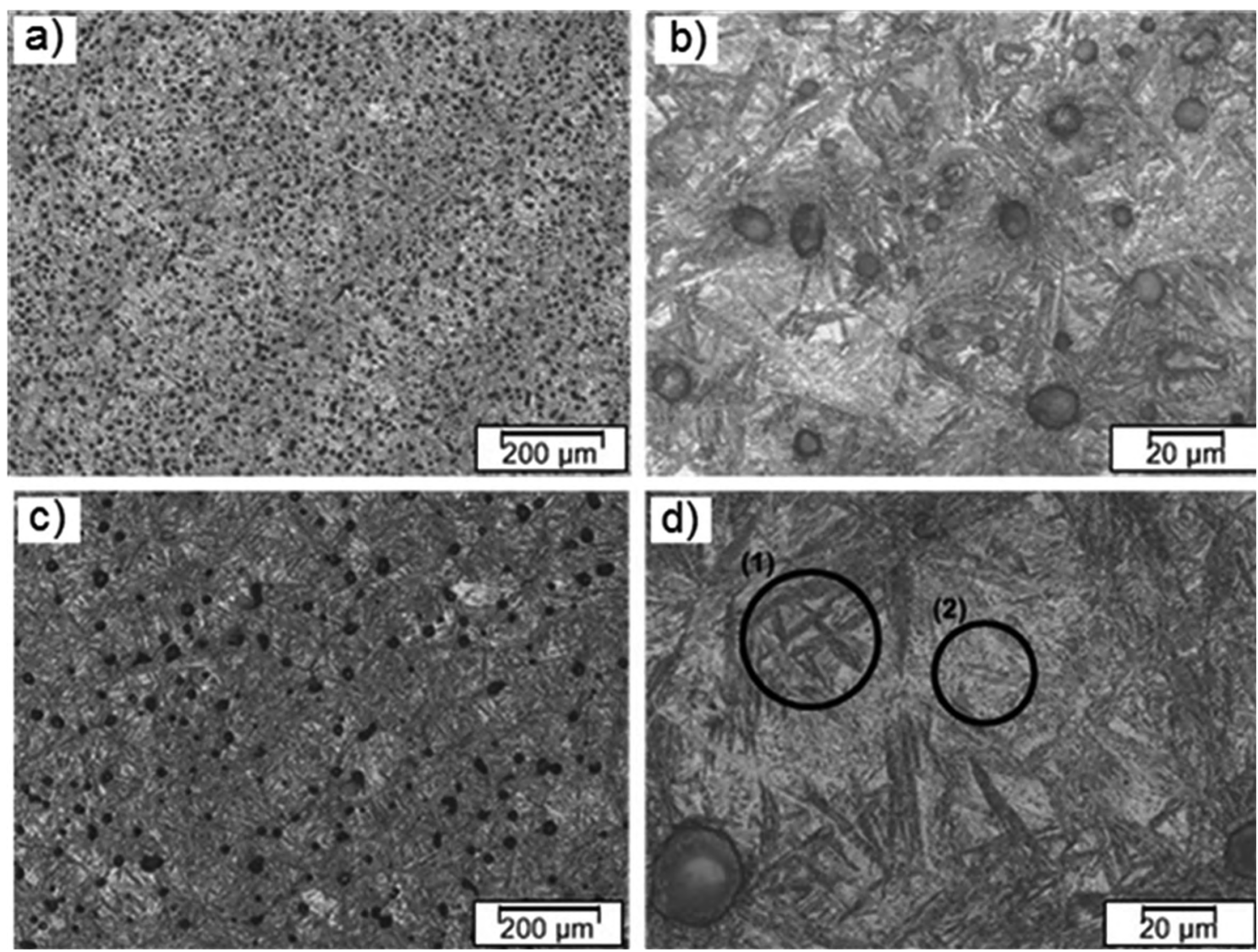

Figure 7. Microstructures of (a-b) pressed and (c-d) injection molded samples sintered at $1400^{\circ} \mathrm{C}$. Optical microscope, Marble etching. 


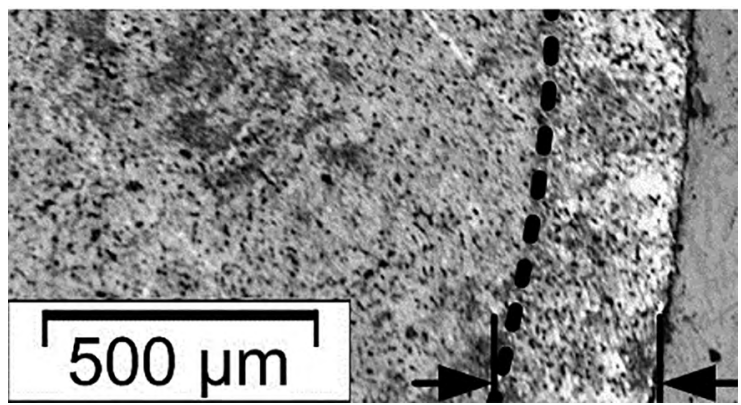

Figure 8. Optical microscopy of a pressed sample border sintered at $1350{ }^{\circ} \mathrm{C}$.

Table 3. Chemical analysis via EDS of injection molded sample sintered at $1375^{\circ} \mathrm{C}$.

\begin{tabular}{lcccccc}
\hline & $\mathbf{C}$ & $\mathbf{C r}$ & $\mathbf{M o}$ & $\mathbf{V}$ & $\mathbf{M n}$ & $\mathbf{S i}$ \\
\hline Rim & - & 4.61 & 1.21 & 1.57 & - & 0.52 \\
Core & 4.42 & 4.61 & 1.22 & 1.32 & 0.25 & 0.59 \\
\hline
\end{tabular}

In this study, the mechanical behavior was evaluated predominantly by hardness, as this property is significantly influenced by the densification obtained during sintering. For the injection molded samples, an overall raise in hardness (Figure 9) can be observed from $170 \mathrm{HV} 10$ to $402 \mathrm{HV} 10$ when increasing the sintering temperature from $1250^{\circ} \mathrm{C}$ to $1430^{\circ} \mathrm{C}$, respectively. The pressed samples, however, exhibit higher hardness at lower sintering temperatures and lower hardness at higher sintering temperatures when compared to the injection molded samples. At $1415^{\circ} \mathrm{C}$, the hardness is within the same range for both shaping methods confirming a comparable densification.

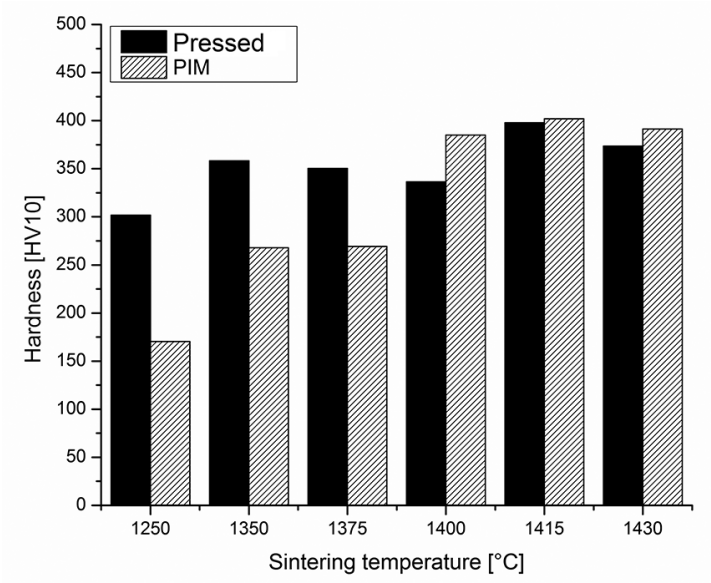

Figure 9. Hardness of pressed and injection molded samples after sintering at temperatures between $1250^{\circ} \mathrm{C}$ and $1430^{\circ} \mathrm{C}$.

Tensile rods sintered at high temperatures, e.g. above $1350^{\circ} \mathrm{C}$, have been geometrically distorted during sintering preventing thereby accurate mechanical measurements. Sintering at lower temperatures resulted in a negligible deformation which allowed testing in as sintered condition and the measured average tensile strength of injection molded samples sintered at $1350^{\circ} \mathrm{C}$ of $1 \mathrm{GPa}(+/-72 \mathrm{MPa})$ is comparable to literature existing data for AISI H13 produced by HIP ${ }^{20}$. Therefore, the proposed processing route offers the potential for high mechanical performance even in a low cost production scheme. Future studies, however, should be performed for further optimization and detailed characterization of the mechanical performance.

\section{Conclusions}

AISI H13 pre-alloyed powder was suitable for shaping by injection molding as well as mechanical pressing. Still, both shaping routes are suitable to pressure less sintering up to temperatures of $\sim 1350{ }^{\circ} \mathrm{C}$. Liquid phase formation and dimensional instability occurred for sintering temperatures higher than $1375{ }^{\circ} \mathrm{C}$. Regardless of the chosen shaping technique the microstructure formed was bainite and homogenous in terms of porosity.

Injection molded samples sintered at $1350{ }^{\circ} \mathrm{C}$ reached values of $400 \mathrm{HV} 10$ as well as tensile strength of $1 \mathrm{GPa}$, similar to values obtained in other processing routes ${ }^{20}$, but in this study, there was no need for secondary heat treatments.

Therefore, the powder injection molding is the most indicated shaping approach and a sintering temperature of $1350^{\circ} \mathrm{C}$ is the one providing homogenous microstructure and good mechanical properties. It is concluded that by adequate choice of the shaping approach and sintering temperature, it is possible to produce AISI H13 steel without any further heat treatment, which reaches mechanical properties as good as the ones obtained in other more expensive or time consuming routes.

\section{Acknowledgements}

We gratefully acknowledge financial support from the "Zentrales Innovationsprogramm Mittelstand (ZIM)", PIM3C, grant \# KF2167002US1, as well as CNPq/CAPES (Science without Borders program - 61/2011, Project "Powder Metallugical Synthesis of Metals and Ceramics"). Research supported by LCME-UFSC.

\section{References}

1. ASM International. ASM Handbook Volume 1: Properties and Selection: Irons, Steels, and High-Performance Alloys. Materials Park: ASM International; 1990. p. 1763-1764;17811786;1840-1842.

2. Berns H, Theisen W. Ferrous Materials - Steel and Cast Iron. Berlin, Heidelberg: Springer; 2008.

3. Deutsche-Edelstahlwerke. Thermodur - 2344 EFS / 2344 EFS Superclean. 2013. Available from: <http://www.dew-stahl. com/fileadmin/files/dew-stahl.com/documents/Publikationen/ 
Werkstoffdatenblaetter/Werkzeugstahl/Warmarbeitsstahl/2344 Thermodur_de.pdf $>$. Access in: 24/3/2015.

4. Schneiders T. Neue pulvermetallurgische Werkzeugstähle. Düsseldorf: VDI-Verlag; 2006.

5. Šuštaršič B, Kosec L, Jenko M, Leskovšek V. Vacuum sintering of water-atomised HSS powders with $\mathrm{MoS}_{2}$ additions. Vacuum. 2001;61(2-4):471-477.

6. Berns H. Warmarbeitsstähle und Legierungen. Düsseldorf: Fortschritt-Berichte VDI; 1982.

7. German RM. Powder Metallurgy of Iron and Steel. Hoboken: Wiley; 1998.

8. Wilmes S. Powder-metallurgical tool steels: Production, properties and application. Stahl und Eisen. 1990;110:93-103.

9. Danninger H, Sohar C, Gierl C, Betzwar-Kotas A, Weiss B. Gigacycle Fatigue Response of PM versus Ingot Metallurgy Tool Steels. Materials Science Forum. 2011;672:23-30.

10. Karlsson $\mathrm{P}$, Gåård $\mathrm{A}$, Krakhmalev $\mathrm{P}$, Bergström J. Galling resistance and wear mechanisms for cold-work tool steels in lubricated sliding against high strength stainless steel sheets. Wear. 2012;286-287:92-97.

11. Godec M, Batič BS, Mandrino D, Nagode A, Leskovšek V, Škapin SD, et al. Characterization of the carbides and the martensite phase in powder-metallurgy high-speed steel. Materials Characterization. 2010;61(4):452-458.

12. Wentzcovitch A, Ambrozio Filho F, da Silva LCE, das Neves MDM. Sintering of AISI M-2 High Speed Steel with the Addition of NbC. Materials Science Forum. 2012;727-728:90-95.

13. Bureš R, Saxl I, Fáberová M. Quantification of Carbide Distribution in PM Tool Steels with Niob Addition. Key Engineering Materials. 2011;465:310-313.

14. Liu RT, Xiong X. Tribological properties of sulfur-containing high-speed steels at elevated temperature. Transactions of Nonferrous Metals Society of China. 2013;23(6):1674-1680.

15. Mu SH, Cao CL, Zhang XL, Xiang Z, Mao X. The Impact of Grinding on Surface Integrity of Powder-Metallurgy High-Speed Steel (S390). Applied Mechanics and Materials. 2014;442:52-57.

16. Liu YH, Ning YQ, Yao ZK, Fu MW. Hot deformation behavior of the 1.15C-4.00Cr-3.00V-6.00W-5.00Mo powder metallurgy high speed steel. Materials \& Design (1980-2015). 2014;54:854-863.

17. Zhang D, Li Z, Xie L, Xiao YF, Yin FC. Powder metallurgy of high speed-steel produced by solid state sintering and heat treatment. International Journal of Materials Research. 2015;106(8):870-876.

18. Sustarsic B, Kosec L, Dolinsek S, Podgornik B. The characteristics of vacuum sintered M3/2 type HSSs with MoS2 addition. Journal of Materials Processing Technology. 2003;143-144:98-104.

19. Šuštaršič B, Kosec L, Kosec M, Podgornik B, Dolinšek S. The influence of $\mathrm{MoS}_{2}$ additions on the densification of water-atomized HSS powders. Journal of Materials Processing Technology. 2006;173(3):291-300.

20. Bayer E, Seilstorfer H. Pulvermetallurgisch durch heißisostatisches Pressen hergestellter Warmarbeitsstahl X40CrMoV5 1. Archiv für das Eisenhüttenwesen. 1984;55(4):169-176.

21. Schroeder RM, Binder C, Klein AN. Sinterability and microstructure formation of a Hadfield steel produced by MIM. In: EURO PM 2013 - European Powder Metallurgy Congress \& Exhibition; 2013 Sep 15-18; Gothenburg, Sweden.

22. Gmbh DE. 1.2344 X40CrMoV5-1.2015. Available from: $<$ http:// www.dorrenberg.es/download/aceros/DOE/1.2344_deu.pdf $>$. Access in: 24/3/2015.

23. Kind, Gmbh CE, Kg C. 1.2344 X40CrMoV5-1.2015. Available from: $<$ http://www.kind-co.de/en/pdf/downloads_wz_s/USD. pdf $>$. Access in: 24/3/2015.

24. Hryha E, Nyborg L, Alzati L. Dissolution of carbon in Crprealloyed PM steels: effect of carbon source. Powder Metallurgy. 2015;58(1):7-11.

25. Danninger H, Gierl C, Kremel S, Leitner G, Jaenicke-Roessler $\mathrm{K}, \mathrm{Yu} \mathrm{Y}$. Degassing and deoxidation processes during sintering of unalloyed and alloyed PM steels. Powder Metallurgy Progress. 2002;2(3):125-140.

26. Nash P, Wen CJ, Phillips M, Lumpkins E. The influence of dew point of a $\mathrm{N} 2 / 10 \% \mathrm{H} 2$ atmosphere on the sintering and the mechanical properties of FC0208. In: International Conference \& Exhibition Advances in Powder Metallurgy \& Particulate Materials, 1995; 1995 May 14-17; Seattle, WA, USA.

27. Speaker RF, Phillips MA, Mironets S. Carbon control for sintering atmospheres. In: International Conference \& Exhibition Advances in Powder Metallurgy \& Particulate Materials, 1995; 1995 May 14-17; Seattle, WA, USA.

28. Schroeder R, Ramos Filho AI, Binder C, Klein AN. Adjusting the Sintering Cycle of a Hadfield Sintered Steel Produced by Metal Injection Molding. Materials Research. 2015;18(Suppl. 2):83-90. 


\section{Erratum}

In the article "Effect of Processing Route on the Microstructure and Mechanical Properties of Hot Work Tool Steel”, DOI number: http://dx.doi.org/10.1590/1980-5373-MR-2016-0726, published in Materials Research, vol.20(6): 1518-1524, in the page 1521:

Where was written:

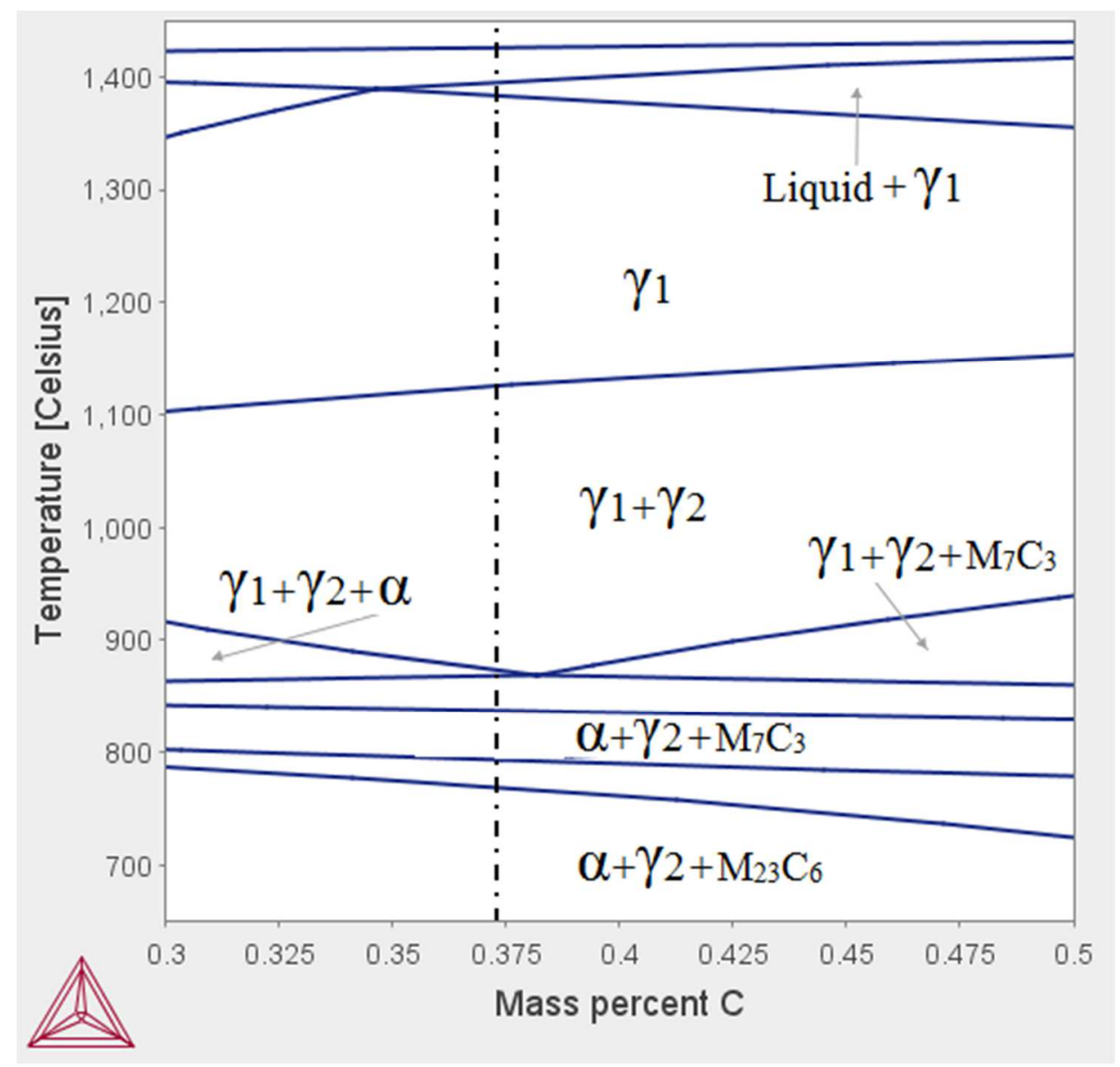

Figure 3. Phase diagram for the AISI H13 alloy (Thermocalc(r)software) according to the carbon content (wt.\%). The dashed line indicates the composition of the samples processed in this study. 
Should be read:

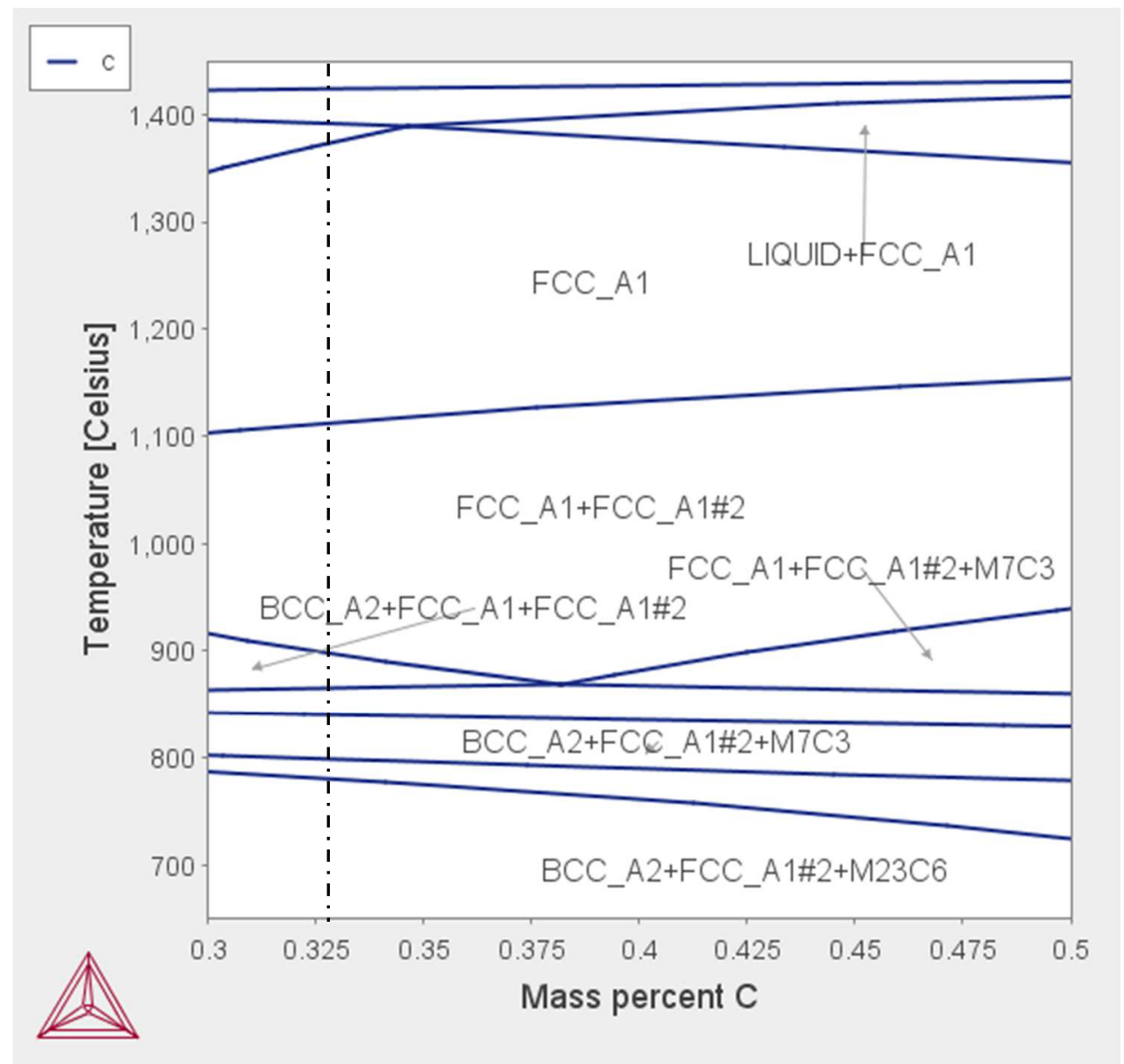

Figure 3: Phase diagram for the AISI H13 alloy (Thermocalc(r) software) according to the carbon content (wt.\%). The dashed line indicates the composition of the samples processed in this study.

The diagram presented in Figure 3 had an error concerning the phases nomenclature. In this diagram the phase FCC_A1 corresponds to the Austenitic phase and the phase indicated by the Thermocalc ${ }^{\circledR}$ software as FCC_A1\# represents a carbide phase, most likely type MC, which has a face-centered cubic structure.

The authors gratefully aknowledge Prof. Hélio Goldenstein for identifying this figure error and inform the authors about it. We also would like to acknowledge Prof. Hélio Goldenstein and Arthur Seiji Nishikawa for checking the original Thermocalc ${ }^{\circledR}$ file and generate new graphs, introduced in this document. 